\title{
Utilization of Arduino Control in Mitigating the Hybrid Harmonics of DC/AC Inverter

\author{
N.Amutha Priya
}

\begin{abstract}
This Paper deals with the implementation of Harmonics distortion in distribution system by using the method of hybrid of active filter and passive filters. The active filter is used to reduce the distortion present in the output. Boost converter is used to increase the voltage level. This boost converter is connected to the inverter, which is designed by using the MOSFET as a switch. In practical application the pulses for the inverter is given by using the Arduino control. By using this hybrid method, the total harmonics distortion is reduced to below the acceptable limit. Simulation for this proposed method is done by using the MATLAB simulink. Initially, fast fourier transform may found to mitigate harmonics. But emerging technologies like Arduino control is proved to simple and economical in carrying out the same task effectively.
\end{abstract}

Index Terms: Harmonics, Arduino, THD, MATLAB.

Keywords: In Practical Application The Pulses For The Inverter Is Given By Using The Arduino Control.

\section{INTRODUCTION}

In today's world, our environment is prone to depend on the supply from renewable energy to the maximum. Renewable energy sources like solar, wind, fuel cell, etc are commonly utilized in our country. Solar cells provide DC output voltage which has to be converted to AC for operating majority of our household and industrial appliances. Inverters come into role to convert DC supply to AC. But the operation of semiconductor switches in the buck-boost converter circuit causes harmonics in the inverter output. In order to supply an undistorted AC power to the appliances, harmonic suppression/ cancellation/ mitigation techniques are used. This paper aims to design a voltage source inverter with minimal harmonics. Hybrid harmonic mitigation technique which is a combination of series active filter and shunt passive filter is used for analyzing the factors indicating the level of harmonics in AC output. While using the Active filters alone it provides more complex control system. So, to get a better stability we added hybrid filter of both passive filters and active filter. By using this we can tune circuit the circuit at the fixed frequency. We can eliminate the resonance issue and it is

Manuscript received on 14 April 2021 | Revised Manuscript received on 12 May 2021 | Manuscript Accepted on 15 September 2021 | Manuscript published on 30 September 2021. * Correspondence Author

N. Amutha Priya*, Assistant Professor - EEE, Rohini College of Engineering and Technology, Vallioor. Email Id: a.amazing13@gmail.com

(C) The Authors. Published by Lattice Science Publication (LSP). This is an open access article under the CC-BY-NC-ND license (http://creativecommons.org/licenses/by-nc-nd/4.0/)

more reliable. In this project, a hybrid harmonic mitigator is designed to analyze the PV supplied inverter system performance in comparison to the traditional mitigation methodologies.

\section{GRID CONNECTED INVERTER}

In this section, analysis of each unit of the power converter circuit is made.Fig. 1 display the converter topology that is adopted. It describes that the buck-boost converter which operates at high frequency of $20 \mathrm{KHz}$ is fed with DC supply. The output of this buck-boost converter is found to be a rectified voltage in the form of sinusoidal wave with same rms value as the grid voltage. This rectified voltage is then fed to a swapping inverter having full-bridge polarity. The swapping inverter operates at the grid frequency of $50 \mathrm{~Hz}$ Low frequency operation leads to low switching losses together with reduced harmonic content. This major advantage is exhibited by the proposed inverter topology. Normally, the need of utilizing a step-up transformer depends on the applied dc sourced input voltage. Fig.1 outlines the operation and the topology of buck-boost converter[1]. In this literature, duty cycle, D is evaluated regularly under the stated frequency levelwith the usage of Pulse Width Modulation (PWM) technique for applying switching pulses to the inverter's semiconductor switches.

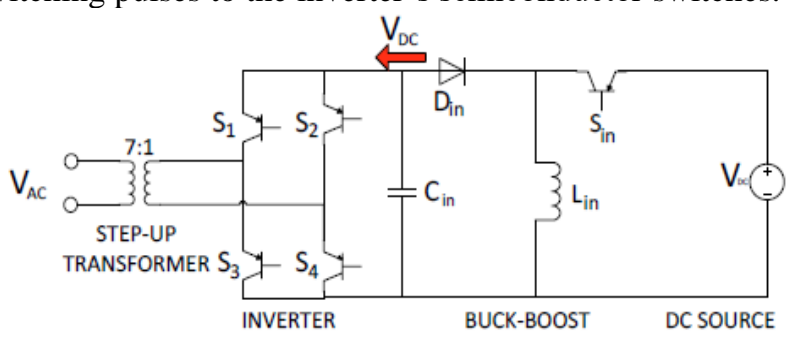

Fig.1 Topology of proposed converter circuit

The produced voltage waveform is compared with the known $20 \mathrm{KHz}$ triangular waveform. The generation of required pulses for the buck-boost converter is obtained by this comparison. The demanded sinusoidal wave is obtained at the required grid frequency with the aggregation of various signals which are used in converter applications namely, harmonic cancellation. The rectified output is obtained and is normally represented as $\mathrm{dc}_{\text {out }}$. Proper synchronization of the inverter is made with the buck-boost converter and grid voltage. When the output voltage of buck-boost converter becomes zero or minimum at least, the inverter's switching pair gets changed. This results in the swapping of polarity of the output voltage of inverter. Finally, the required ac voltage is obtained at the output of the proposed converter circuit.

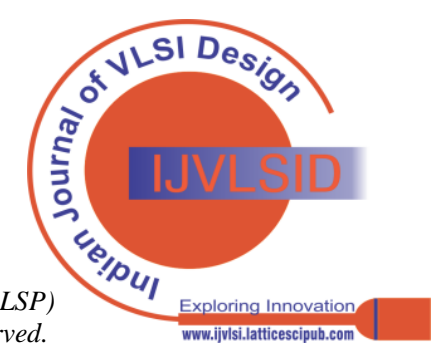




\section{HARMONICS OF INVERTER CIRCUIT}

According to the source, the inverter output current 's harmonics are grouped as switching and low frequency harmonics. While, the switching harmonics are related to thePWMcircuits ofthe inverter circuit, lower frequency harmonics occurrence is due to deficiencies in the inverter output current's control. To the maximum, filtration of switching harmonics is carried out at the output of the inverter itself. However, lower order harmonics are at frequencies much closer to the fundamental frequency. Thus, without the impairment of the fundamental current waveform, it is very difficult to filter out these harmonics.Within each inverter circuit, the crystalcontrolled clocks are totally independent. Hence, synchronization of the output current harmonics related to the PWM is made with the clock circuits within the inverter controller itself and is totally uncorrelated. Since the harmonic distortion which arise in each inverter is uncorrelated, this way of arrangement offers a recognized power quality benefit and thus cancellation will take place in multiple inverters systems. But harmonics which arise due to the current controller's performance will have a differentbehaviour. Normally, at a particular time, when a current reference waveform is produced within the inverter circuit, this specifies the magnitude and power factor of the output current in accordance with the active and reactive power generation requirements.In each inverter, the current reference waveform must be synchronized to the common network voltage waveform for a grid connected system. This leads to high degree of correlation of harmonics produced by individual converters since any low order harmonics resulting from controller deficiencies will also be synchronized to the common network voltage. This makes the lower order harmonics from each inverter to be additive. Usually, it is the grid-connected inverter which drivesthe current against the supply voltage and impedance and these are not fixed quantities as well. The performance of the grid connected inverter is verymuch dependent on the operating conditions of the grid. Hence, the control of current injection into the grid network is very difficult than the control of supply current to fixed loads such as motor windings or isolated consumer load systems. The fidelity of output current waveform is reliably dependent on the current control loop's tuning impact.But the changes in the characteristics of grid supply mean that it is not possible to achieve an optimally tuned output current loop at all times [2]. Normally, tuning of the inverter output current is madewith the adjustment of controller settings while monitoring the low order harmonics. A large number of harmonics can be reduced and total harmonic distortion (THD) can be minimized using the trial and error method. While tuning the circuit, a point is normally reached where further tuning does not produce any further improvement in THD. But with proper adjustments in the controller tuning process, however, it is possible to alter which harmonics are suppressed while maintaining the total harmonic distortion reasonably constant [3-9]. This is mainly because of the interaction between the dynamics of the controller and supply together with line inductance. The block diagram shown in fig.2 depicts the overall picture of the system used.

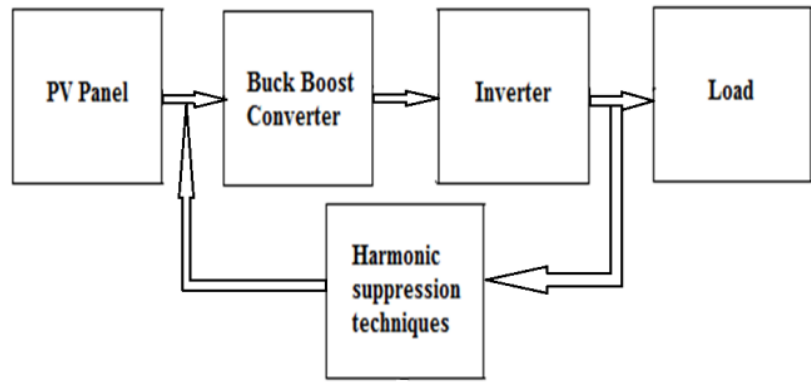

Fig.2 Block Diagram of the system

\section{SIMULATIONRESULTS}

MATLAB simulation is used for the analysis of effect of harmonics on the inverter performance.

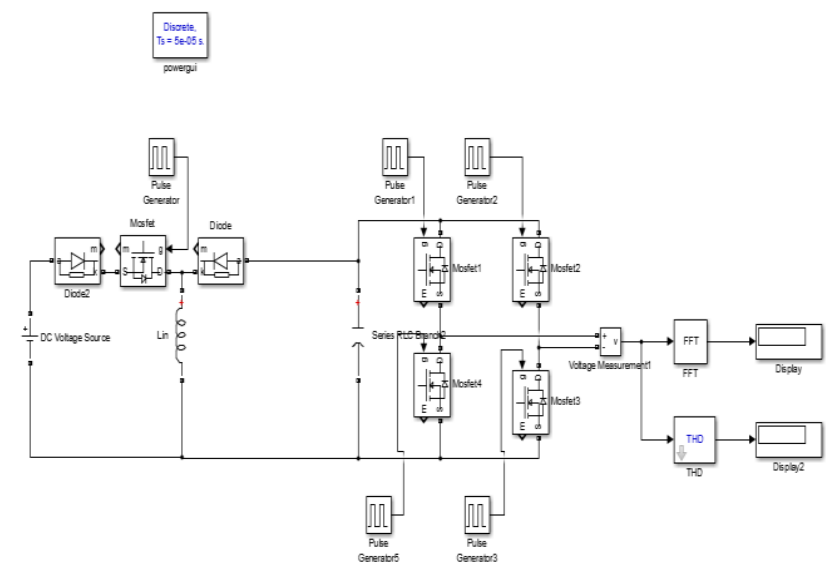

Fig. 3 Inverter without harmonic suppression circuit

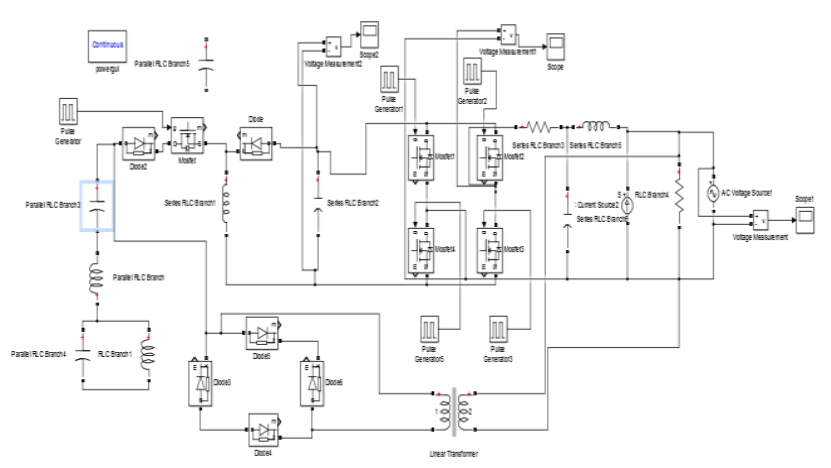

Fig. 4 Inverter with harmonic suppression circuit

The simulation circuits shown in fig. 3 and 4 are used for comparative analysis of harmonics influence in the inverter circuit. Fig. 3 and 4 depicts the inverter circuit which investigates the inverter output without and with harmonics suppression components respectively. On simulating with circuit in fig. 3 , the obtained buck-boost converter output of the circuit is picturized in fig. 5. The chopper voltage reaches $1.8 \mathrm{~V}$ as an impulse and starts to decrease exponentially in slow pace. 


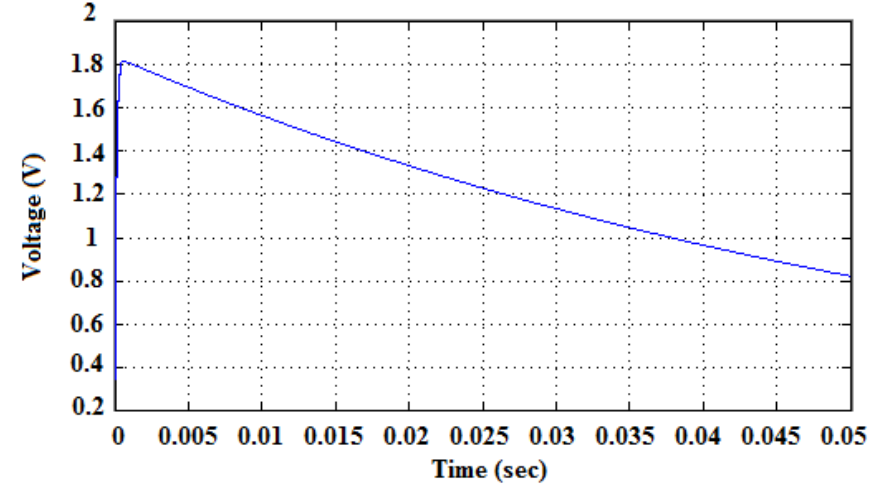

Fig. 5 Buck-Boost converter output without harmonic compensation

On simulating circuit in fig. 4, the inverter output which is a square wave with the voltage amplitude of $1.8 \mathrm{~V}$ initially is obtained as shown in fig. 6 . The total harmonic distortion value of the inverter output is found to be 0.595 .

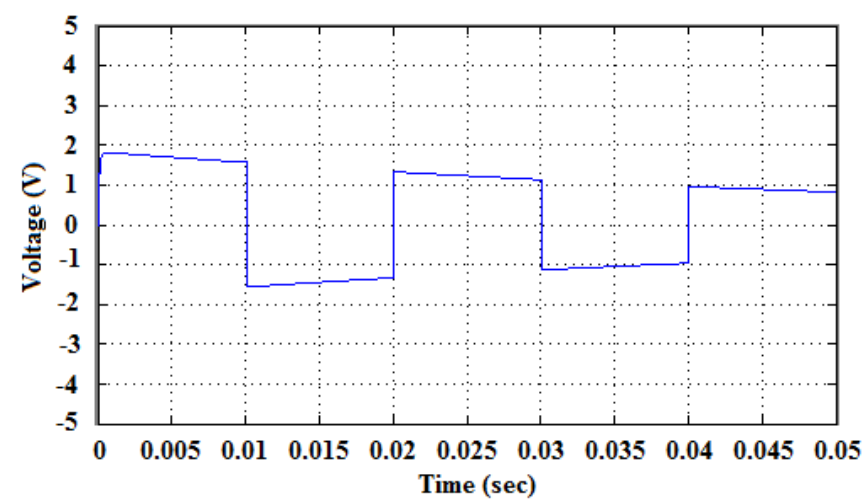

Fig. 6 Inverter output without harmonic compensation

Fig. 4 depicts the inverter circuit with the harmonic suppression circuit combining both active and passive filters. The effect of harmonics gets reduced with the indication of THD value to be -23.1. Fig. 7 shows the buckboost converter output whose voltage amplitude is around $8 \mathrm{~V}$. Finally, fig. 8 clearly picturizes the complete effect of filter application where the filtered output with a voltage amplitude of $22 \mathrm{~V}$ is obtained as shown.

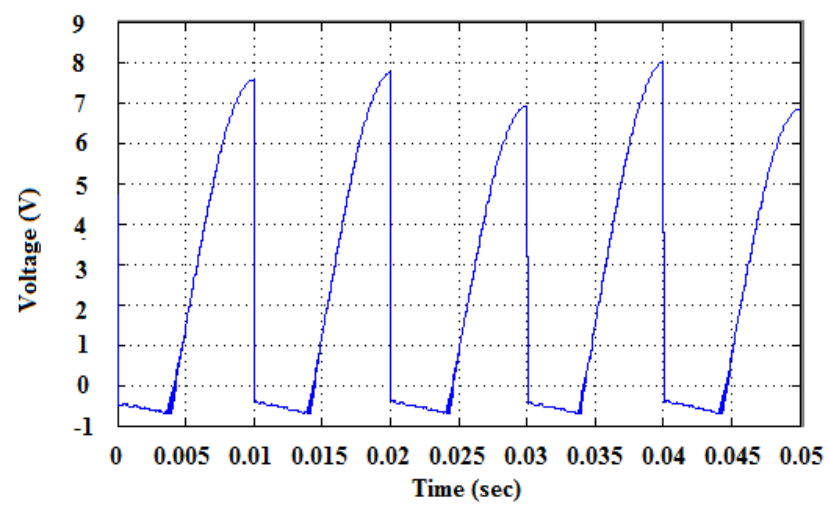

Fig. 7 Buck-Boost converter output with harmonic compensation

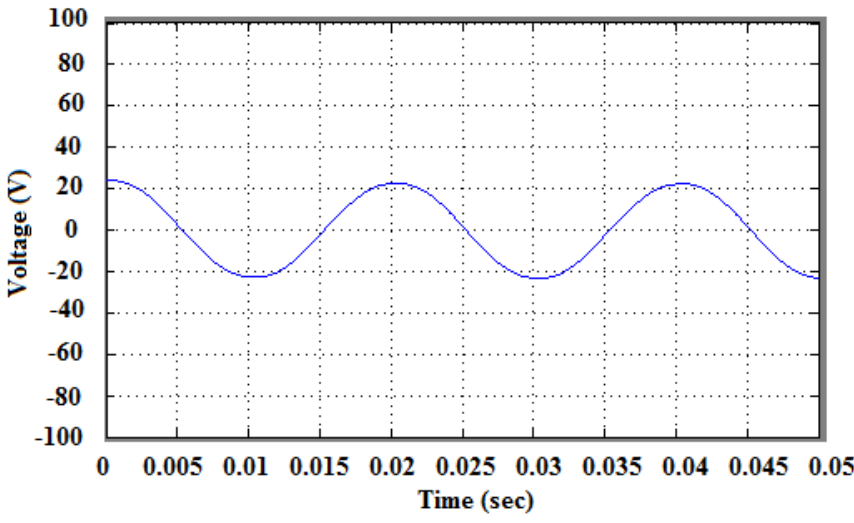

Fig. 8 Inverter output without harmonic compensation

\section{HARDWARE IMPLEMENTATION}

The hardware system of the project setup is shown in fig.9. Arduino controller is used to mitigate the hybrid harmonics impact in the inverter system. The setup is made using the electrical circuit as shown in fig. 1 with the inclusion of Arduino control to deliver the switching pulses to the MOSFET switches. Tuning effect influences the harmonics generation and with fine tuning of the controller gain and time constant, the harmonics level is suppressed highly from 0.6 to -22.5 . This is almost equivalent to the simulation results obtained using MATLAB. Thus, Arduino control is proved to be effective in mitigating the hybrid harmonics.

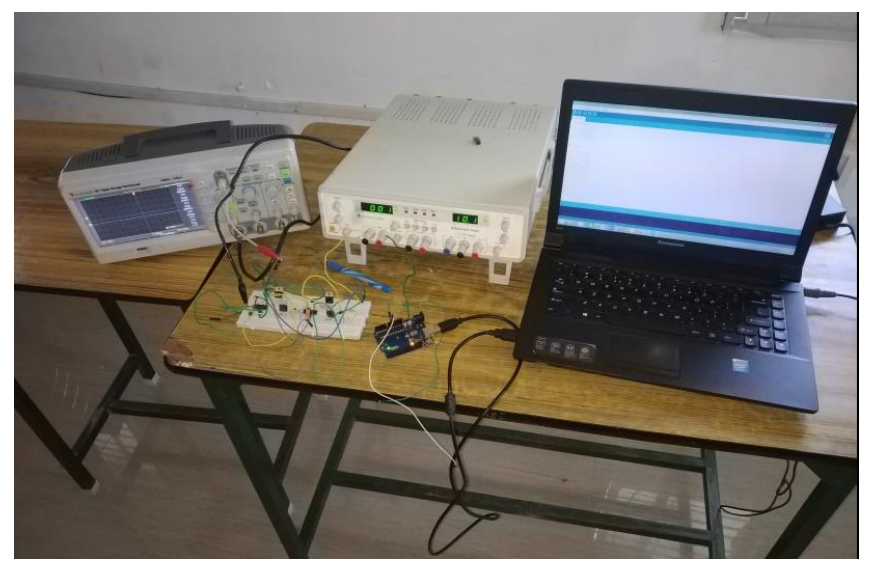

Fig. 9 Hardware setup

\section{CONCLUSION}

In this paper, the role of utilization of Arduino control technique in mitigating the hybrid harmonics in DC/AC inverter has been investigated.The harmonics will be suppressed by using the hybrid technique i.e., with the combination of series active filter andshunt passive filter.Simulation work has been done by using the MATLAB software. Also, the hardware setup is implemented to verify the simulated results in reality. The results are found to be satisfiable in mitigating the harmonics impact in the inverter circuit and also, the proposed system used in this work is found to be cheap and robust.

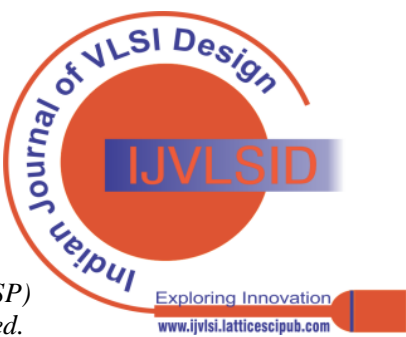




\section{REFERENCES}

1. Ioannis D. Bouloumpasis, Panagis N. Vovos, Konstantinos G. Georgakas, Nicholas A. Vovos, "Harmonic Cancellation of PV-supplied DC/AC Converter without Stabilizing Input Capacitors," Elsevier, IFAC-PapersOnLine49-27,2016, pp. 035-040. [CrossRef]

2. Ali HazdianVarjini, "Harmonic control techniques for inverters and adaptive active power filters," University of Wollongong, Research online, 1998.

3. Donald Grahame Holmes, Brendan P. McGrath, "Opportunities for Harmonic Cancellation with Carrier-Based PWM for Two-Level and Multilevel Cascaded Inverters," IEEE Transactions on Industry Applications, Vol. 37, No. 2, 2001, pp. 574-582. [CrossRef]

4. Qing Zhong, Junjie Feng, Gang Wang, Haifeng Li, "Feedforward Harmonic Mitigation Strategy for Single-Phase Voltage Source Converter," Journal of Electrical and Computer Engineering,2018, pp.110. [CrossRef]

5. Ioannis D. Bouloumpasis, Panagis N. Vovos, Konstantinos G. Georgakas, Nicholas A. Vovos, "Current Harmonics Compensation in Microgrids Exploiting the Power Electronics Interfaces of Renewable Energy Sources,” Energies, Vol. 8, 2015, pp. 2295-2311. [CrossRef]

6. Ali Abbas, Tahir Izhar, Umar Tabrez Shami, Adil Salman, Hanya Amjad, "Synthesis of Low Cost Inverter Using Harmonic Reduction through Pulse Pattern," International Journal of Scientific \& Engineering Research, Vol. 7, No. 10, 2016, pp. 798-803.

7. Matthew Armstrong, David J. Atkinson, C. Mark Johnson,Tusitha D. Abeyasekera, "Low Order Harmonic Cancellation in a Grid Connected Multiple Inverter System Via Current Control Parameter Randomization," IEEE Transactions on Power Electronics, Vol. 20 (4), 2005, pp. 885-892. [CrossRef]

8. Lu, Junwei, Zhao, Xiaojun, Li, Hui, "Harmonic Analysis in Microgrid and Distributed Energy System Using Harmonic Balance Method," IEEE PES Asia-Pacific Power and Energy Engineering Conference, 2016, pp. 1-5. [CrossRef]

9. Dibyendu Bhadra, Rajnish Kumar Meena, "Power Quality Improvemen By Harmonic Reduction Using Three Phase Shunt Active Power Filter With p-q \& d-q Current Control Strategy," Thesis, National Institute of Technology, Rourkela, 2015.

\section{AUTHORS PROFILE}

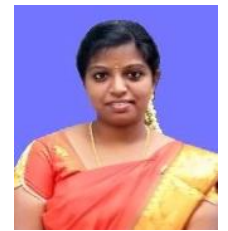

Dr.N.Amutha Priya, received her B.E. degree in Electrical \& Electronics Engineering from Government College of Engineering, Tirunelveli. She worked as Lecturer at Ponjesly College of Engineering, Nagercoil. Then, she received her MBA degree in Human Resource Management from Indira Gandhi National Open University, New Delhi and M.E. degree in Control \& Instrumentation from St. Xavier's Catholic College of Engineering, Nagercoil. Then she continued her career as Assistant Professor in Universal College of Engineering \& Technology, Vallioor. Next, she pursued her Doctoral degree in Electrical Engineering faculty with INSPIRE fellowship from DST, New Delhi. Then she worked as an Assistant Professor in Kamaraj College of Engineering \& Technology, Madurai District. She was awarded with Doctorate degree in the Faculty of Electrical Engineering from Anna University, Chennai. Now, presently she is working as an Assistant Professor in the EEE department of Rohini College of Engineering and Technology, Kanyakumari. Her research interests include demand side management, power system and control systems. She has 12 conference and 5 journal publications. She is a reviewer for several journals.

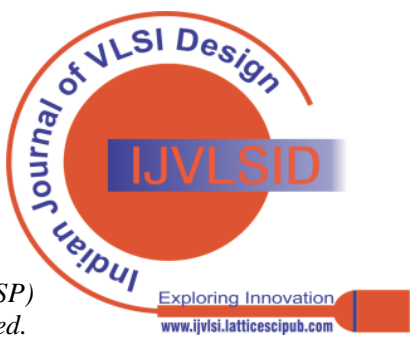

